\title{
Supporting Parenting to Promote Children's Social and Emotional Well-being
}

\author{
Philip B. Smith \\ University of Prince Edward Island \\ Jacquie Brown \\ Triple P International \\ Steven Feldgaier \\ Healthy Child Manitoba and University of Manitoba \\ Catherine M. Lee \\ University of Ottawa
}

\begin{abstract}
The effects of parenting on the healthy development of children and adolescents, and on preventing behavioural, emotional, and social problems, are pervasive. A public health approach to parent education and support can have major impact on the mental health of Canadians. Many of the values and strategic directions advocated by the Mental Health Commission of Canada can be realized in a population-based system for parent support such as the Triple P Positive Parenting Program. Triple P's core principles, program components, and means of implementation are described, with illustrations from across Canada.
\end{abstract}

Keywords: parenting support, children's well-being, population-level interventions, Mental Health Commission of Canada, Triple P Positive Parenting Program

\section{RÉSUMÉ}

Les parents jouent un rôle clé dans le développement des enfants et des jeunes, ainsi que dans la prévention des problèmes comportementaux, émotionnels et sociaux. Une approche axée sur la santé publique à l'égard de l'éducation et de l'appui aux parents pourrait avoir un impact majeur sur la santé mentale

Philip B. Smith, Department of Psychology, University of Prince Edward Island; Jacquie Brown, Triple P International; Steven Feldgaier, Healthy Child Manitoba, Government of Manitoba and Department of Clinical Health Psychology, University of Manitoba; Catherine M. Lee, School of Psychology, University of Ottawa.

Catherine M. Lee is now a Triple P trainer.

Correspondence concerning this article should be addressed to Philip B. Smith, Department of Psychology, University of Prince Edward Island, 550 University Avenue, Charlottetown, PE C1A 4P3. Email: smithp@upei.ca 
des Canadiens et Canadiennes. Le programme de pratiques parentales positives Triple $\mathrm{P}$ offre une façon de mettre en œuvre plusieurs des valeurs et des directions stratégiques proposés par la Commission de la santé mentale du Canada. Nous expliquons les principes et les éléments clés de ce programme, ainsi que la façon d'implantation, avec des exemples à travers le Canada.

Mots clés : appui aux parents, bien-être des enfants, interventions au niveau de la population, Commission de la santé mentale du Canada, programme de Pratiques parentales positives Triple P

The Senate report Out of the Shadows at Last: Transforming Mental Health, Mental Illness and Addiction Services in Canada (Kirby \& Keon, 2006) described mental health as the orphan of the Canadian health care system. The orphan metaphor — which implies being bereft of care, protection, and advantages — applies especially to mental health issues faced by children and youth, so some have dubbed the mental health of young Canadians “the orphan's orphan" (Kutcher, McLuckie \& Child and Youth Advisory Committee, Mental Health Commission of Canada, 2010). This apt moniker reflects the extreme need for action. To address this need the Mental Health Commission of Canada (MHCC) Child and Youth Advisory committee developed Evergreen: A Child and Youth Mental Health Framework (Kutcher et al., 2010), providing values and directions to guide diverse stakeholders in addressing child and youth mental health in Canada. The values include: (a) human rights; (b) dignity, respect, and diversity; (c) best available evidence; (d) choice, opportunity, and responsibility; (e) collaboration, continuity, and community; (f) access to information, programs, and services. These values should be applied towards efforts in prevention; promotion of mental health and mental health literacy to reduce stigma; intervention and ongoing care, with a special focus on timely intervention through primary care; as well as in research and program evaluation. These values aspire towards a respectful system in which diverse individuals are understood within the context of their circumstances and are offered an array of coordinated, evidence-based services that permit them to optimize their potential.

The blueprint for change outlined by the MHCC established priorities and issued a call for action on strategies to create a Canadian mental health system that addresses the needs of those living with mental disorder as well as the needs of their families (MHCC, 2012). Six strategic directions were outlined:

1. Promotion of mental health and prevention of mental disorder.

2. Fostering recovery.

3. Providing access to services.

4. Reducing disparities in risk factors and access to services.

5. Collaborating with First Nations, Inuit, and Métis to address their mental health needs.

6. Mobilizing leadership to improve knowledge and foster collaboration.

Like the values described in the Evergreen document, these strategic directions contain little that warrants debate. It makes eminent sense to focus on interventions at all stages of the process of developing, living with, and recovering from mental health problems. Stakeholders must learn from other milieus and develop solutions that are appropriate in diverse Canadian contexts (Bartram \& Chodos, 2013). 
In this article we illustrate how many of the MHCC directions are addressed via implementation of the Triple P Positive Parenting Program — an evidence-based, multilevel population-health parenting programoffered in provinces across Canada. The implementation of Triple $\mathrm{P}$ demonstrates one way that directions $1,3,4,5$, and 6 of the blueprint can be put into action.

\section{THE IMPORTANCE OF POSITIVE PARENTING}

Family environments both contribute to and are affected by children's problems (Grusec, 2011). Children flourish when their parents and other caregivers provide a safe, stimulating environment that encourages exploration and mastery (Lee, 2010). On the other hand, they are vulnerable when they live in a context of neglect, parental conflict, and harsh parenting (Clément, Gagné, \& Lee, 2014). Compared to their peers, children and youth with mental health problems are likely to grow up in families with higher levels of parental psychopathology, child-rearing practices that contribute to the child's dysfunction, higher aggression between parents, poorer family communication, and higher levels of parental stress (Kazdin \& De Los Reyes, 2008). Of all the risk factors for children's adjustment problems, parenting is one of the most modifiable. To address these issues, a variety of programs have been designed to support parents in providing a positive environment for their children (Sanders, 2012).

Parenting programs with the strongest research evidence are those grounded in social learning theory (Bandura, 1971). Patterson's observational research on families (e.g., Patterson, 1982) identified coercive interactional cycles in which family members inadvertently reward one another for undesirable behaviours. This work influenced the development of a number of parenting interventions in the United States (e.g., Defiant Children, Barkley, 1987; Helping the Noncompliant Child, Forehand \& McMahon, 1981; Incredible Years, Webster-Stratton \& Reid, 2010; and Parent-Child Interaction Therapy, Eyberg \& Calzada, 1998), Canada (e.g., Community Parent Education Program (COPE), Cunningham, Bremner, \& Secord-Gilbert, 1998), and Australia (e.g., Triple P-Positive Parenting Program, Sanders, 1999). These parenting programs based on social learning theory are all designed to teach parents to increase positive interactions with their children, provide rewards for appropriate behaviour, set clear limits, reduce their use of commands, and become more consistent in parenting (Taylor \& Biglan, 1998).

Programs vary in structure, modality, intensity, and the parent populations for which they are designed. For example, the Incredible Years program involves group sessions in which therapists facilitate discussion of videos of parent-child interaction and engage parents in role playing. Tailored for different ages, variations of the Basic series are for parents of babies (nine 2-hour sessions), toddlers (12 sessions), preschool, and elementary school aged children (18-20 sessions). Parents with personal and interpersonal risk factors that might contribute to coercive parent-child interaction may be offered an additional 10-12 sessions in

the ADVANCE group program. Complementary training programs are provided to teachers and to children (Webster-Stratton \& Reid, 2010).

The Community Parent Education Program (COPE) was developed in Canada as a means to strengthen parent-child relationships, increase cooperation, and solve common problems. COPE sessions are designed for parents of children aged 3-12 years, and teenagers (13-18). Groups of 25-30 parents participate in a series of ten 2-hour sessions involving videotaped vignettes of problematic situations, large-group and 
subgroup discussions of solution development, leader modelling, and application of strategies in homework assignments (Cunningham, Bremner, Secord, \& Harrison, 2009).

Systematic reviews, meta-analyses, and benchmarking studies provide evidence that parenting programs derived from social learning theory produce changes in parent behaviour, child behaviour, and parent adjustment (Lee, Horvath, \& Hunsley, 2013; Michelson, Davenport, Dretzky, Barlow, \& Day, 2013; Sanders, Kirby, Tellegen, \& Day, 2014). Within the context of the MHCC's first priority - to promote mental health, prevent problems, and reduce stigma - the MHCC blueprint accords central importance to increasing parents' capacity to encourage the healthy social and emotional wellbeing of their children. The more detailed example of Triple P Positive Parenting offers an evidence-based program that has been widely implemented across Canada. It is given within a public health framework to promote positive parenting at a population level (Sanders, 2010). This ambitious approach is designed to promote healthy parent-child relationships, and prevent ineffective parenting practices, among families at lower risk as well as among families already experiencing significant challenges. A public health perspective implies complementarity between program components, and an integrated approach to parent education and support that is relevant to all parents in the population.

\section{THE TRIPLE P POSITIVE PARENTING PROGRAM}

Originating in Australia and delivered in over 25 countries, Triple P was developed over more than 30 years of community practice, evaluation research, and revision (Sanders, 2012). Triple P is a suite of programs offered at different levels of intensity; a number of variants are tailored to meet the particular needs of subgroups of parents. Triple $\mathrm{P}$ is available across diverse modalities, including seminars, brief consultations, individual meetings, group sessions, telephone contact, workbooks, and services online (Sanders, 2012). Triple $\mathrm{P}$ is ranked first internationally for evidence base among family skills training programs (United Nations Office on Drugs and Crime, 2010). Triple P improves parenting practices, leading to beneficial short- and long-term social, emotional, and behavioural outcomes in children, parent satisfaction and efficacy, parental adjustment, and interparental relationship (Sanders et al., 2014). A recent population trial in Ireland that investigated Triple P implementation in communities reported reductions in the numbers of children with emotional and behavioural problems; decreases in parental stress and distress; and increases in parents' reports of positive relationships with their children, engagement in positive parenting, and appropriate use of discipline. Parents also reported increased willingness to seek help in future (Fives, Pursell, Heary, Nic Gabhainn, \& Canavan, 2014). In a landmark population trial in South Carolina, Triple P yielded large effect sizes for population indicators of substantiated child maltreatment, child out-of-home placements, and child maltreatment injuries (Prinz, Sanders, Shapiro, Whitaker, \& Lutzker, 2009).

Canadian applications of Triple $P$ have included analysis of clinical measures at a practitioner and agency level, and process evaluations exploring, for example, facilitators and barriers to parent participation (e.g., Houlding, Schmidt, Stern, Jamieson, \& Bord, 2012) and practitioner adherence (e.g., Taylor, Asgary-Eden, Lee, \& LaRoche, 2015). A Social Sciences and Humanities Research Council of Canada-funded study ongoing in parts of Quebec will offer the first Canadian population outcome formal evaluation of Triple $\mathrm{P}$ (focused on child maltreatment). 


\section{The Principle of Self-Regulation}

Triple $\mathrm{P}$ promotes the development of self-regulation in parents, children, and service providers (Sanders \& Mazzucchelli, 2013). Through Triple P parents acquire the knowledge, skills, and confidence they need to enlarge their repertoire of options for promoting their children's healthy development, and responding to concerning behaviour, in a manner consistent with their cultural and personal values. Parents, in turn, promote their children's self-regulation. Benefits of self-regulation apply to practitioners as well, in strengthening their modelling for parents and enhancing their efficacy. Additionally, self-regulation is an attribute of successful organizations; therefore Triple P encourages administrators - in collaboration with practitioners - to identify positive outcomes and develop procedural guidelines accompanied by effective training and support. Triple P practitioners come from diverse professional backgrounds and work in myriad practice sites. Professionals already engaged with parents build on their skills through training and accreditation in one or more Triple $\mathrm{P}$ programs, and subsequently incorporate Triple P practice within their core responsibilities.

Given the range of parents' needs and preferences, Triple P offers five levels of intervention and a menu of resources for parents within each level. Reflecting the self-regulatory model, parents choose the resources that best match their needs and preferences. Core principles of positive parenting addressed in all levels are:

- safe and engaging environments,

- positive learning environments,

- assertive discipline,

- realistic expectations, and

- parental self-care.

The principle of self-regulation is designed to ensure transfer of skills to a variety of contexts and ensures the maintenance of gains after the program ends.

\section{The Principle of Minimal Sufficiency: A Suite of Five Levels}

Canadian parents are notoriously time-crunched (Marshall, 2009), and they are challenged to find ways of adding participation in some type of parenting support program to their busy family calendar. To maximize the reach of effective interventions in an efficient and sustainable manner, Triple $\mathrm{P}$ offers the minimally sufficient intervention for each parent's needs. The principle is to link parents with interventions that aid development of the knowledge, skills, and confidence they require, utilizing the least intensive and expensive resources to achieve that goal. (Details can be found at: http://www.triplep.net/glo-en/home.)

Level 1, Universal Triple P. The least intensive manner in which Triple $\mathrm{P}$ is delivered is via websites, conventional media, social media, and community messaging. It is designed both to communicate effective parenting strategies and to destigmatize support-seeking for concerns about parenting. All parents can receive

and benefit from foundational messages about positive parenting but parents who require more intensive supports are informed about resources and reassured that concerns about parenting and support-seeking help are normal. 
Level 2, Selected Triple P. Level 2 involves either large-group (2-hour) seminars (e.g., Raising Confident, Competent Children) or brief (20 minutes each) consultations with Triple P-trained practitioners who are already engaged with the family in health settings, child care, or school. Selected Triple P is designed to provide information and support to parents in the general population who are concerned about relatively minor issues. Help-seeking for parents who are in need of more intensive interventions is normalized.

Level 3, Primary Care Triple P. Primary Care is designed for parents whose children display discrete behaviour problems in the absence of broader child or family dysfunction, and who would benefit not only from information sharing but also from focused active skills training. Triple P-trained practitioners who already have professional contact with the family provide several brief (15-30 minutes) consultations, including review of informational "Tip Sheets" accompanied by active skills training. Special attention is paid to generalizability of the skills learned to other behaviours or other children in the family. This brief intervention capitalizes on existing professional relationships and provides an efficient way to help many parents with specific concerns.

Level 4, Intensive Triple P. Level 4 is designed for parents whose children are displaying some problem behaviours or parents who would benefit from learning parenting skills that could be applied to a broad range of target behaviours. When delivered in person, Level 4 is offered in two formats: Standard in ten (1hour) individual sessions and Group, in which the same material is covered, in five (2-hour) group sessions plus three individual telephone consultations. A variant for parents of children with disabilities is known as Stepping Stones Triple P. Alternatively, Self-help Workbooks and Triple P Online - consisting of eight to ten modules - are designed for parents whose geographic location, schedule, child-care responsibilities, or service preferences preclude in-person meetings with a practitioner.

Level 5, Adjunctive Support. A small proportion of parents who participate in Standard Triple P experience a variety of risk factors and require the addition of a more intensive intervention. Level 5 includes a menu of modules addressing issues such as inter-parental communication, coping with stress and mood management for parents, and additional practice in handling parent-child issues that can be tailored to parents' needs. Pathways Triple P serves parents at risk of child maltreatment. Another level 5 variant is Lifestyle Triple P, focusing on the challenges faced by parents of overweight or obese children.

The MHCC highlighted the need to ensure access to the right services. With its multiple levels of parenting support at different intensities the Triple $\mathrm{P}$ approach addresses this issue in an innovative manner. Triple $\mathrm{P}$ training is offered to practitioners who already interact with families via a range of service delivery systems including health (e.g., public health nurses, family physicians, mental health clinicians), education (e.g., school counsellors, classroom teachers, administrators, school clinicians), early learning and child care (e.g., child care staff), and social services and child welfare (e.g., family support workers, social workers) amongst others. The availability of Triple $P$ through multiple service delivery systems already used by families reduces stigma and removes obstacles, enhancing access. The principle of minimal sufficiency ensures that scarce resources are deployed as efficiently as possible. Economic analysis of the Triple P system demonstrates high cost effectiveness through the prevention of child mental health disorders (e.g., Mihalopoulos, Sanders, Turner, Murphy-Brennan, \& Carter, 2007) and child abuse, neglect, and out-of-home placement (e.g., Aos et al., 2011). Triple $\mathrm{P}$ has been shown to be sensitive to the diverse needs and preferences of communities, agencies, and parents in many countries including Australia (e.g., Morawska et al., 2011) and Canada (e.g., 
Houlding, Schmidt, Stern, Jamieson, \& Borg, 2012). The tailoring of the most effective configuration of programs for each context requires collaborative implementation processes.

\section{IMPLEMENTATION}

Triple P International (TPI), the licensed disseminating organization for the Triple P system, has developed a TPI Implementation Framework (the Framework) which blends concepts from implementation science (Fixsen, Naoom, Blasé, Friedman, \& Wallace, 2005; Glasgow, Vogt, \& Boles, 1999), with years of Triple P dissemination experience. A TPI Implementation Consultant (IC) introduces implementing organizations to the five phases of execution:

- engagement;

- commitment and contracting;

- implementation planning;

- training and accreditation; and

- implementation and maintenance.

Each phase of the Framework includes a set of goals and key activities that are addressed in a logical sequence, although concurrent activity in several phases of the Framework is possible.

Engagement. From the large menu of Triple P programs, implementing organizations must select the right program and practices, to ensure it fits with their needs. This requires a sound knowledge of the community and the organization as well as a good understanding of the Triple P system. The IC uses dialogue and guided questions to assist organizations in determining the practices and program that are the best fit for their desired outcomes. Key considerations include gaps and needs in services within the community, workforce capacity, cultural acceptability, community context, and service delivery processes. During the Engagement Phase the organization and TPI begin to develop an understanding of issues to address to ensure effective implementation and sustainability.

Commitment and contracting. Successful implementation is dependent upon clearly articulated and agreed-upon outcomes and goals. Building on the dialogue and understanding established in the engagement phase, organizations and ICs develop a shared grasp of the scope of implementation by confirming the target population, how the proposed TP service fits within the community, and by calculating the capacity needed to meet the initiative's intended reach and goals.

Implementation planning. Simply training practitioners is insufficient to ensure that a program is delivered with the fidelity required to achieve desired outcomes (Garbacz, Brown, Spee, Polo, \& Budd, 2014). In the Implementation Planning phase communities, organizations, and practitioners are supported as they strategize and prepare for sustained and effective service delivery. This is achieved by considering the organization and community readiness and capacity in areas such as: planning for and effecting organization change, data collection and analysis, evaluation, logistical support and quality improvement, and particularly practitioner preparation and support. 
Training and accreditation. Training and accreditation is provided by TPI Accredited Trainers. All training modules are developed and delivered using best practices in adult education. Planning and preparing the community, organization, and practitioners prior to training considerably increases practitioners' ability to benefit from the training and apply with fidelity the knowledge, skills, and strategies they have learned (Romney, Israel, \& Zlatevski, 2014). Further developing their competence and maintaining fidelity is achieved through regular Peer Support Network meetings, linking with the Triple P Practitioner website, workshops, and symposia.

Implementation and maintenance. Following planning and training, the implementing organization is ready to offer Triple P service to families. Sound data are collected diligently so that over the first 6 months of service delivery the effectiveness of both the practitioners and the support systems can be assessed. This enables corrective action should it be necessary to improve the service delivery process. Continuously applied improvement cycles using a Plan-Do-Study-Act methodology (Deming, 1986) promote ongoing improvement and sustained effective service delivery providing for achieving the desired outcomes and goals.

Population health approach-community implementation. For implementation of Triple $\mathrm{P}$ at a population level, the phases and activities of the Framework replicate and cascade through the system, with participants providing leadership and guidance at each level to engage partners in the key activities. Roles and responsibilities within the system need to be clearly articulated and agreed upon (see Figure 1).

\section{TAILORED IMPLEMENTATIONS OF TRIPLE P IN CANADA}

In the final section we describe a sample of tailored implementations of Triple $\mathrm{P}$ in Canada. These include: (a) a variety of province-wide initiatives, supported by provincial government funding; (b) initiatives by individual organizations or a voluntary community collaborative that are not governed as provincial systems; (c) a large-scale trial that is funded by a research granting agency; and (d) implementation tailored with Aboriginal communities.

\section{Government/Policy-Supported Implementations}

Manitoba. In 2005, the Government of Manitoba began the provincewide implementation of the Triple P System as part of its Healthy Child Manitoba strategy. (Details can be found at: http://www.gov. $\mathrm{mb} . \mathrm{ca} /$ healthychild/index.html.) This initiative brought together government departments, regional health authorities, school divisions, child welfare agencies, early learning and child care centres, as well as numerous community agencies in partnerships with Healthy Child Manitoba to train practitioners in the levels of Triple P best fitting the needs of the families they serve. Short-term goals for this initiative were to upskill the current multidisciplinary workforce with additional evidence-based tools for use in supporting families and to increase parents' access to accurate parenting information, support, and assistance as needed. Longerterm goals see the provision of these services contributing as part of the Healthy Child Manitoba strategy to reduce the prevalence of children with social, emotional, and behavioural difficulties.

To encourage agencies, school divisions, and others to participate as partners in this initiative, Healthy Child Manitoba has underwritten the costs of training and travel to training for service providers, and has provided all Triple $P$ resources needed to deliver these services to parents at no cost by serving as the central 


\section{Figure 1}

\section{Roles and Responsibilities for Community Implementation of Triple P System (Positive Parenting Program)}

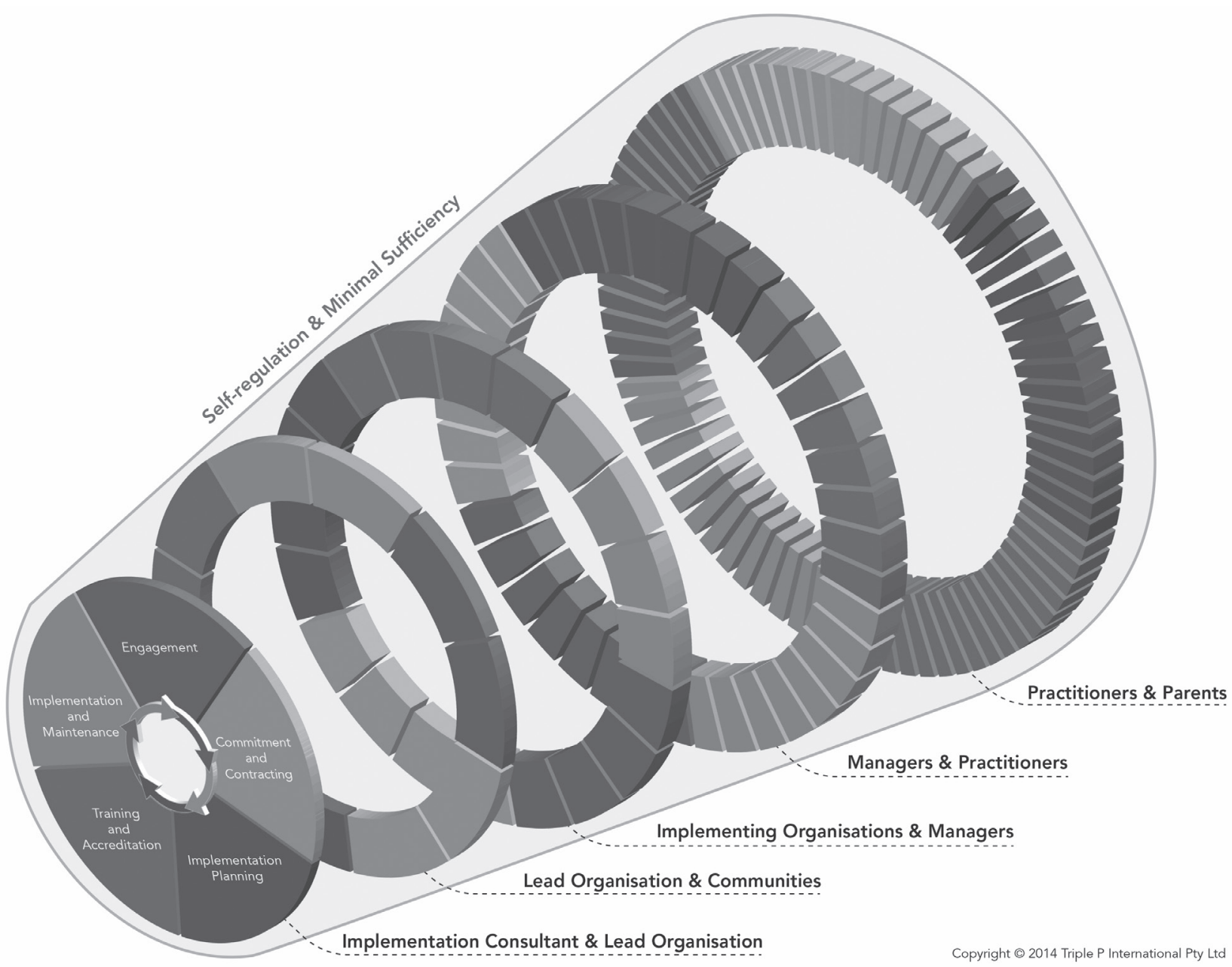

Copyright 2014 by Triple P International Pty Ltd. Adapted with permission.

purchaser of these resources from Triple P International. To date, more than 2,400 professionals from more than 350 organizations have been trained and accredited in Triple P. These practitioners are supported by a small team of Triple P coordinators at Healthy Child Manitoba who serve as the primary link between the provincial government and community-level service providers.

To serve the needs of Manitoba families without easy access to direct face-to-face Triple P services (for example, families living in small, remote communities) the Triple P Parent Line was introduced in 2011 by Healthy Child Manitoba in partnership with the Provincial Health Contact Centre, providing free, confidential 
telephone support through the opportunity to speak directly with Triple P counsellors about parenting questions and concerns. The phone line also serves as a vehicle to direct parents to services in their community and to facilitate referral when that may be needed. Increasingly, parents are engaging in the self-directed variant of Triple $\mathrm{P}$ with the availability of phone consultation as an added support.

As Manitoba has a significant Francophone population, Healthy Child Manitoba also undertook from the outset to work closely with Triple P International to facilitate the translation of many of the training materials and parenting resources into French. Triple P training for Francophone practitioners and Triple P services for Francophone families are now available.

The goal of utilizing this initiative to upskill the workforce has also led to innovative partnerships. For example, Healthy Child Manitoba has partnered with the Early Childhood Education Program at the University College of the North to include Triple P training and accreditation as part of the curriculum for students in this 2-year diploma program. Graduates of this program now are able to implement Triple P when they then return to their home communities across northern Manitoba.

Alberta. In recent years the Provincial Alberta Human Service has initiated and funded a population health implementation of Triple P through Parent Link Centres. More than 700 professionals in child care, health centres, and parenting education programs throughout Alberta have been trained. There is an active website (http://www.triplep-parenting.net/alb-en) to provide parenting tips and information about the location of Triple P practitioners and what services are being offered where. The Stay Positive campaign, designed to de-stigmatise participating in parenting education, offers tips through brief messages and issues a Triple P Tip Paper two to three times per year which includes local stories and parenting advice.

Prince Edward Island. After several years of consultations among community and governmental stakeholders about how best to address needs for parent education and support, the Prince Edward Island government announced in its 2014 budget address that Triple P will be implemented in that province. The intent is for comprehensive but gradual implementation to be spread over 5 years. Triple P is funded jointly by the four government departments with responsibility for health, education, child and family services, and justice.

\section{ORGANIZATION- OR COMMUNITY-SUPPORTED IMPLEMENTATIONS}

Ontario. Triple $\mathrm{P}$ is available in over 20 regions or communities across Ontario. Triple $\mathrm{P}$ has been initiated by committed organizations or communities providing service to children and families (AsgaryEden \& Lee, 2012). The Triple P Ontario website (http://www.triplepontario.ca) offers information about organizations providing Triple $\mathrm{P}$, the location of practitioners, and upcoming courses. There is no overarching service delivery structure in Ontario; however, through voluntary collaborations and the development of the Ontario Triple P Network, communities have coordinated a number of multisector Triple P initiatives providing broad reach. Through the Network agencies share implementation knowledge and support new agencies considering implementation of Triple $\mathrm{P}$.

A more detailed example of a community-wide implementation is the implementation of Triple $\mathrm{P}$ in eastern Ontario (the United Counties of Stormont, Dundas and Glengarry, the City of Cornwall, and the United Counties of Prescott Russell). In 2009 a number of agencies in eastern Ontario shared an interest 
in bringing Triple P to their communities. Training for practitioners began in 2010 and has continued with increasing numbers of organizations being involved. In 2011 a steering committee was formed and in 2012 Memoranda of Understanding were signed between participating organizations. Established in 2014, the Healthy Families Coalition of Eastern Ontario includes 18 organizations as active partners and 13 other supporting organizations that collectively offer all levels of Triple P. A toll-free number and email (info@) mytriplep.ca) facilitate central intake and provide information. Additionally, parents can register for courses and sessions through the website, enabling participation with no stigma or referral required.

The steering committee has guided the implementation through the use of implementation science, particularly the National Implementation Research Network's Active Implementation Frameworks which form the foundation of the Triple P Implementation Framework.

All of this has been achieved through reallocating and sharing existing resources. One of the most significant outcomes has been the community collaboration achieved through organizations working together with a common, multilevel evidence-based program that can be tailored to the community needs and delivered according to each organization's mandate.

British Columbia. In British Columbia Triple $\mathrm{P}$ is available through more than a dozen organizations, predominantly on Vancouver Island where the initial implementation of Triple $\mathrm{P}$ was supported by local government. More recently Surrey and Fraser Valley have provided Triple P services. As with Ontario, the collaborative approach has been the responsibility of local cooperation between organizations and across sectors.

\section{Research-Supported Implementation}

Quebec. A trial, funded by the Social Sciences and Humanities Research Council of Canada, is examining whether implementation of Triple P in areas in Montreal and Quebec City will yield reductions in child maltreatment by comparing areas in which Triple $\mathrm{P}$ is offered with matched communities that do not offer Triple P. Training is being conducted in 2015-2017.

\section{Implementation Tailored to Aboriginal Communities}

Over the last 5 years several provinces, including Saskatchewan, Manitoba, British Columbia, Alberta, and Ontario, have undertaken initiatives specifically tailored to the unique needs of Aboriginal communities. In Saskatchewan an implementation of Triple P was initiated by an Indian Child and Family Services agency who invited the collaboration of other community service providers to develop a population health approach. In Manitoba, practitioners from a range of diverse agencies in more than 30 First Nations communities have now participated in Triple P training.

\section{CONCLUSION}

The implementation of Triple $P$ in various parts of Canada provides an excellent example of putting the values elaborated by the MHCC Child and Youth Advisory committee into action. It is clear that programs designed to support parents in the provision of positive environments for their children promote the human 
rights of the child. The flexibility of the Triple P program allows it to be tailored to the needs of diverse communities and parents. There is abundant evidence of the efficacy of the program. With its emphasis on self-regulation, the Triple P approach offers agencies, parents, and children choice. The implementation framework developed by TPI is a model of collaboration as these services are introduced and sustained in a community. Finally, the focus on minimal sufficiency allows for thrifty use of resources, so that access can be as broad as possible. In addition, the vibrant networks that have developed are an inspiring example of how knowledge about ways to support parents in supporting their children is shared.

\section{REFERENCES}

Aos, S., Lee, S., Drake, E., Pennuci, A., Klima, T., Miller, M., . . Burley, M. (2011). Return on investment: Evidencebased options to improve statewide outcomes (Document No. 11-07-1201). Olympia: Washington State Institute for Public Policy.

Asgary-Eden, V., \& Lee, C. M. (2012). Implementing an evidence-based parenting program in community agencies: What helps and what gets in the way? Administration and Policy in Mental Health and Mental Health Services Research, 39, 478-488. doi:10.1007/s10488-011-0371-y

Bandura, A. (1971). Social learning theory. New York, NY: General Learning Press.

Barkley, R. A. (1987). Defiant children. New York, NY: Guilford Press.

Bartram, M., \& Chodos, H. (2013). Changing directions, changing lives: The mental health strategy for Canada: Calling for critical deliberation on implementation. Canadian Journal of Community Mental Health, 32(4), 1-8. doi:10.7870/cjcmh-2013-001

Clément, M-E., Gagné, M-F., \& Lee, C. M. (2014.) Understanding and preventing child maltreatment. Canadian Journal of Community Mental Health, 33, 1-12. doi:10.7870/cjemh-2014-012

Cunningham, C. E., Bremner, R., \& Secord-Gilbert, M. (1998). The community parent education (COPE) program: A school-based family systems oriented course for parents of children with disruptive behavior disorders. Unpublished manuscript, McMaster University and Chedoke-McMaster Hospitals, Hamilton, ON.

Cunningham, C. E., Bremner, R., Secord, M., \& Harrison, R. (2009). COPE, The Community Parent Education Program: Large group community based workshops for parents of 3 to 18 year olds. Hamilton, ON: COPE Works.

Deming, W. E. (1986). Out of the crisis. Cambridge, MA: MIT Press.

Eyberg, S. M., \& Calzada, E. J. (1998). Parent-child interaction therapy: Procedures manual. Unpublished manuscript, University of Florida, Gainesville, FL.

Fives, A., Pursell, L., Heary, C., Nic Gabhainn, S., \& Canavan, J. (2014) Parenting support for every parent: A population-level evaluation of Triple P in Longford Westmeath: Final report. Athlone, Ireland: Longford Westmeath Parenting Partnership (LWPP).

Fixsen, D. L., Naoom, S. F., Blase, K. A., Friedman, R. M, \& Wallace, F. (2005). Implementation research: A synthesis of the literature. Tampa, FL: University of South Florida, Louis de la Parte Florida Mental Health Institute, The National Implementation Research Network (FMHI Publication \#231).

Forehand, R. L., \& McMahon, R. (1981). Helping the noncompliant child. New York, NY: Guilford Press.

Garbacz, L. L., Brown, D. M., Spee, G. A., Polo, A. J., \& Budd, K. S. (2014). Establishing treatment fidelity in evidencebased parent training programs for externalizing disorders in children and adolescents. Clinical Child and Family Psychology Review, 17, 230-247. doi:10.1007/s10567-014-0166-2

Glasgow, R. E., Vogt, T. M., \& Boles, S. M. (1999). Evaluating the public health impact of health promotion interventions: the RE-AIM framework. American Journal of Public Health, 89(9), 1322-1327.

Grusec, J. E. (2011). Socialization processes in the family: Social and emotional development. Annual Review of Psychology, 62, 243-269. doi:10.1146/annurev.psych.121208.131650

Houlding, C., Schmidt, F., Stern, S. B., Jamieson, J., \& Borg, D. (2012). The perceived impact and acceptability of Group Triple P Positive Parenting Program for Aboriginal parents in Canada. Children and Youth Services Review, 34(12), 2287-2294. doi:10.1016/j.childyouth.2012.08.001 
Kazdin, A., \& De Los Reyes, A. (2008). Conduct disorder. In R. Morris \& T. Kratochwill (Eds.), The practice of child therapy (pp. 207-247). Mahwah, NJ: Lawrence Erlbaum Associates.

Kirby, M. J. L., \& Keon, W. J. (2006). Out of the shadows at last: Transforming mental health, mental illness and addiction services in Canada. Ottawa, ON: Standing Senate Committee on Social Affairs, Science and Technology. Retrieved from http://www.parl.gc.ca/content/sen/committee/391/soci/rep/pdf/rep02may06part1-e.pdf \& http:// www.parl.gc.ca/content/sen/committee/391/soci/rep/pdf/rep02may06part2-e.pdf

Kutcher, S., McLuckie, A., \& Child and Youth Advisory Committee, Mental Health Commission of Canada. (2010). Evergreen: A child and youth mental health framework for Canada. Calgary, AB: Mental Health Commission of Canada. Retrieved from http://www.forcesociety.com/sites/default/files/Evergreen_Framework_English_ July2010_final.pdf

Lee, C. M. (2010). Families matter: Psychology of the family and the family of psychology. Canadian Psychology. 51(1), 1-8. doi:10.1037/a0018282

Lee, C. M., Horvath, C., \& Hunsley, J. (2013). Does it work in the real-world? The effectiveness of treatments for psychosocial problems in children and adolescents. Professional Psychology: Research and Practice, 44(2), 81-88. doi:10.1037/a0031133

Marshall, K. (2009). The family work week. Perspectives. Statistics Canada (Catalogue no. 75-001-X), 5-13. Retrieved from http://www.statcan.gc.ca/pub/75-001-x/2009104/pdf/10837-eng.pdf

Mental Health Commission of Canada. (2012). Changing directions, changing lives: The mental health strategy for Canada. Calgary, AB: Author. Retrieved from: http://strategy.mentalhealthcommission.ca/pdf/strategy-text-en.pdf

Michelson, D., Davenport, C., Dretzke, J., Barlow, J., \& Day, C. (2013). Do evidence-based interventions work when tested in the "real world"? A systematic review and meta-analysis of parent management training for the treatment of disruptive child behavior. Clinical Child and Family Psychology Review, 16(1), 18-34. doi:10.1007/ s10567-013-0128-0

Mihalopoulos, C., Sanders, M. R., Turner, K. M., Murphy-Brennan, M., \& Cater, R. (2007). Does the Triple P-Positive Parenting Program provide value for money? Australian \& New Zealand Journal of Psychiatry, 41(3), 239-246. doi:10.1080/00048670601172723

Morawska, A., Sanders, M. R., Goadby, E., Headley, C., Hodge, L., McAuliffe, C., . . Anderson, E. (2011). Is the Triple P-Positive Parenting Program acceptable to parents from culturally diverse backgrounds? Journal of Child and Family Studies, 20, 614-622. doi:10.1007/s10826-010-9436-x

Patterson, G. R. (1982). Coercive family process. Eugene, OR: Castalia.

Prinz, R. J., Sanders, M. R., Shapiro, C. J., Whitaker, D. J., \& Lutzker, J. R. (2009). Population-based prevention of child maltreatment: The U.S. Triple P system implementation trial. Prevention Science, 10(1), 1-12. doi:10.1007/ s11121-009-0123-3

Romney, S., Israel, N., \& Zlatevski, D. (2014) Exploration-stage implementation variation: Its effect on the cost-effectiveness of an evidence-based parenting program. Zeitschrift für Psychologie, 222, 37-48. doi:10.1027/2151-2604/ a000164

Sanders, M. R. (1999). Triple P-Positive Parenting Program: Towards an empirically validated multilevel parenting and family support strategy for the prevention of behavior and emotional problems in children. Clinical Child and Family Psychology Review, 2(2), 71-90. doi:10.1023/A:1021843613840

Sanders, M. R. (2010). Adopting a public health approach to the delivery of evidence-based parenting interventions. Canadian Psychology, 51(1), 17-23. doi:10.1037/a0018295

Sanders, M. (2012). Development, evaluation and multinational dissemination of the Triple P-Positive Parenting Program. Annual Review of Clinical Psychology, 8, 345-379. doi:10.1146/annurev-clinpsy-032511-143104

Sanders, M., Kirby, J. N., Tellegen, C. L., \& Day, J. J. (2014). The Triple P-Positive Parenting Program: A systematic review and meta-analysis of a multi-level system of parenting support. Clinical Psychology Review, 34(4), 337-357. doi:10.1016/j.cpr.2014.04.003

Sanders, M. R., \& Mazzucchelli, T. G. (2013). The promotion of self-regulation through parenting interventions. Clinical Child and Family Psychology Review, 16(1), 1-17. doi:10.1007/s10567-013-0129-z

Taylor, W. D., Asgary-Eden, V., Lee, C. M., \& LaRoche, K. J. (2015). Service providers' adherence to an evidencebased parenting program: What are they missing and why? Journal of Child and Family Studies, 24, 50-56. doi:10.1007/s10826-013-9812-4 
United Nations Office on Drugs and Crime. (2010). Compilation of evidence-based family skills training programs. Retrieved from https://www.unodc.org/documents/prevention/family-compilation.pdf

Webster-Stratton, C., \& Herbert, M. (1994). Troubled families-problem children: Working with parents: A collaborative process. Chichester, UK: Wiley.

Webster-Stratton, C., \& Reid, M. J. (2010).The Incredible Years Parents, Teachers and Children Training Series: A multifaceted treatment approach for young children with conduct problems. In J. Weisz \& A. Kazdin (Eds.), Evidence-based psychotherapies for children and adolescents (2nd ed., pp. 194-210). New York, NY: Guilford Press. 